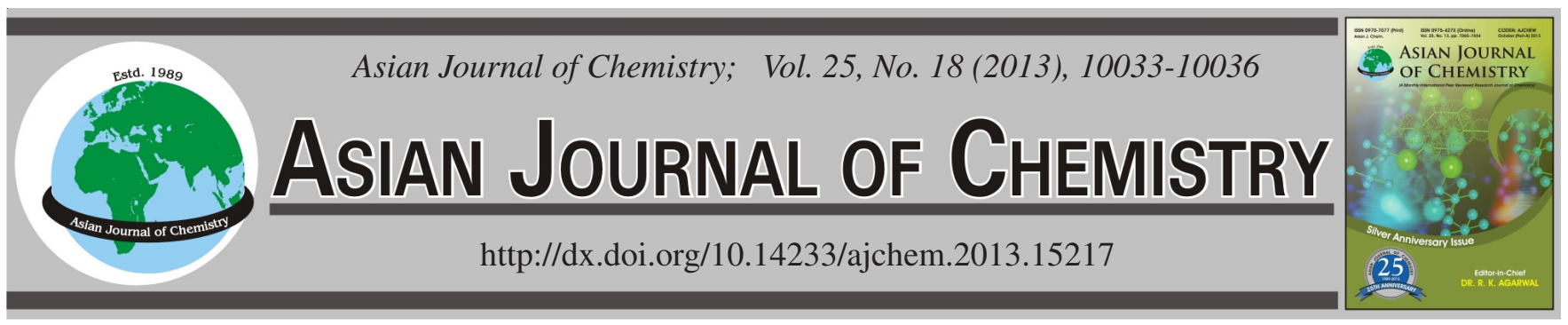

MINI REVIEW

\title{
Antibacterial Mechanism of Chitosan and its Applications in Protection of Plant from Bacterial Disease
}

\author{
B. LI ${ }^{1, *}$, C.L. $\mathrm{SHAN}^{1}$, M.Y. GE ${ }^{1}$, L. WANG ${ }^{1}$, Y. FANG ${ }^{2}$, Y.L. WANG ${ }^{3, *}$, G.L. XIE ${ }^{1}$ and G.C. Sun ${ }^{3, *}$
}

${ }^{1}$ State Key Laboratory of Rice Biology, Institute of Biotechnology, Zhejiang University, Hangzhou 310058, P.R. China

${ }^{2}$ College of Chemistry and Life Sciences, Zhejiang Normal University, Jinhua 321004, P.R. China

${ }^{3}$ State Key Laboratory Breeding Base for Zhejiang Sustainable Pest and Disease Control, Institute of Plant Protection and Microbiology, Zhejiang Academy of Agricultural Sciences, Hangzhou 310021, P.R. China

*Corresponding authors: Fax: +86571 86971680; Tel: +86571 88982412; E-mail: libin0571@zju.edu.cn; wangylaa@yahoo.com.cn; sungc@ zaas.org

Chitosan has showed strong antibacterial activity against a variety of gram-negative and gram-positive bacteria. This paper reviews current and potential agricultural applications of chitosan in preventing bacterial disease in plants according to recent data found in the literature. In particular, the possible and accepted antibacterial mechanisms for chitosan are presented and discussed.

Key Words: Chitosan, Application, Antibacterial activity, Agriculture, Mechanisms of action.

\section{INTRODUCTION}

Chitosan is a modified, natural nontoxic carbohydrate polymer $^{1,2}$. During the past several decades, chitosan and its derivatives have been receiving an increasing attention for its commercial applications ${ }^{3}$. The rapidly growing interest in the new applications of chitosan and its derivatives for agriculture has focused on its potential antivirus, antifungal, in particular antibacterial activities ${ }^{4-8}$. In addition, chitosan has several advantages over other types of bactericide ${ }^{9}$. This review summarizes some of the uses of chitosan and its derivatives in the control of plant bacterial disease and gives an overview of the antibacterial mechanisms involved.

Plant bacterial disease: Chitosan has been shown effective to control several fungal diseases ${ }^{8}$. However, the effect of chitosan on bacterial plant pathogens is poorly documented ${ }^{4-7}$. Nevertheless, the efficiency of chitosan to protect plants against bacterial diseases could be expected since chitosan exhibits bactericidal activity towards a variety of human pathogenic bacteria $^{10,11}$. Recently, several studies on antibacterial activities of chitosan against plant pathogenic bacteria have been carried out (Table-1). As expected, the growth of Xanthomonas sp. pathogenic to Euphorbia pulcherrima was markedly inhibited by chitosan. The antibacterial activity of chitosan against the selected strain R22580 of X. axonopodis pv. poinsettiicola were unaffected by various environmental conditions ${ }^{4}$. Furthermore,
Algam et al. ${ }^{12}$ revealed that chitosan has strong in vitro antibacterial activities against tomato bacterial wilt caused by Ralstonia solanacearum. In addition, N-(benzyl) chitosan derivatives had strong in vitro antibacterial activity against the crown gall disease caused by Agrobacterium tumefaciens and the soft rot disease caused by Pectobacterium carotovora ${ }^{13,14}$ while the commercial formulation Elexa, produced with its chitosan content, exhibited inhibitory effects on the in vitro growth of Pseudomonas lachrymans, the causal agent of bacterial angular leaf $\operatorname{spot}^{15}$.

In addition to in vitro inhibition, chitosan has been used for the control of crown gall of grapes and roses ${ }^{16}$, while bacterial wilt in tomato plants was inhibited by chitosan irrespective of the mode of application ${ }^{12}$. Furthermore, chitosan provided a protective effect against Streptomyces scabies, the causal agent of potato common scab in the field. In some instances, an additive effect of protection was observed when chitosan was used in combination with Streptomyces melanosporofaciens EF-76 ${ }^{17}$. In addition, chitosan-treated plants showed significant responses, reaching $87 \%$ of commercial resistance inducer acibenzolar-S-methyl protection performance against Xanthomonas vesicatoria leaf spot in susceptible tomato plants under greenhouse conditions ${ }^{18}$. Commercial formulation Elexa provided $60 \%$ of protection against the damage caused by bacterial angular leaf spot $(P$. lachrymans) in cucumber in greenhouse conditions ${ }^{15}$. There- 
TABLE 1

APPLICATION OF CHITOSAN AND ITS DERIVATIVE IN THE CONTROL OF PLANT PATHOGENIC BACTERIA

\begin{tabular}{lcccc}
\hline \multicolumn{1}{c}{ Pathogenic bacteria } & Bacterial disease & Antibacterial & Chitosan/derivative & Reference \\
\hline Xanthomonas axonopodis & Poinsettia leaf spot & in vitro & Chitosan & 4 \\
Ralstonia solanacearum & Tomato wilt & in vitro/vivo & Chitosan & 12 \\
Agrobacterium tumefaciens & Fruit tree crown gall & in vitro & N-(Benzyl) chitosan & 13 \\
Erwinia carotovora & Vegetable soft rot & in vitro & N-(Benzyl) chitosan & 13 \\
Streptomyces scabies & Potato common scab & in vivo & Chitosan & 17 \\
Xanthomonas vesicatoria & Tomato leaf spot & in vivo & Chitosan & 18 \\
Pseudomonas lachrymans & Cucumber angular leaf spot & in vitro/vivo & Elexa & 15 \\
Pseudomonas fluorescens & Broccoli head rot & in vitrolvivo & Chitosan & 5,19 \\
Burkholderia seminalis & Apricot fruit rot & in vitro & Chitosan & 11 \\
\hline
\end{tabular}

fore, it could be suggested that chitosan was able to act as a preventative and stimulative agent to protect plants against certain bacterial diseases.

Postharvest bacterial disease: Plant pathogenic bacteria negatively affect a large number of important fruit and vegetables during the growing season and throughout postharvest storage $^{19-21}$. Traditional antimicrobials have been extensively used for many years. Recently, our studies showed that the in vitro growth of Pseudomonas fluorescens causing bacterial head rot of broccoli ${ }^{19}$ and Burkholderia seminalis causing bacterial fruit rot of apricot ${ }^{11}$ were markedly inhibited by chitosan under various environmental conditions. In addition, the antistaling agent comprising 1-2 \% chitosan has good effects in inhibiting the bacteria in the fruit and vegetable in reserving process and has inhibiting effect to the rot of fruit and vegetable. Moreover, it has simple processing technology and low cost and is in accordance with the developmental direction of current antistaling agent ${ }^{22}$.

Furthermore, chitosan and its derivatives have been used as a natural compound to control postharvest pathogenic disease $^{23}$. Li et al..$^{5}$ demonstrated that the disease incidence and the lesion diameter of broccoli inoculated with $P$. fluorescens were significantly reduced when broccoli plants were either pretreated or post-treated with six different combinations of chitosan solutions. In addition, chitosan showed beneficial effect on fruit quality and resistance to decay by preharvest spraying at low concentration and postharvest coating with a higher concentration ${ }^{24}$, which may reduce the incidence of postharvest disease. Therefore, it is evident that chitosan solutions have a potential in the prevention and control of postharvest bacterial disease.

\section{Antibacterial mechanisms}

Cationic nature of chitosan: Researchers have applied multiple techniques to investigate chitosan's antibacterial mode of action ${ }^{25}$. It is generally assumed that the cationic nature of chitosan, conveyed by the positively charged $\mathrm{NH}_{3}$ groups of glucosamine, might be a fundamental factor contributing to its interaction with the negatively charged microbial cell surface, ultimately resulting in impairment of vital bacterial activities $^{25}$. However, the mechanism of the antibacterial activity has not been fully elucidated. Several hypotheses have been proposed as follows:

Bacteriocidal or bacteriostatic?: In general, chitosan is considered to be a bacteriocidal or bacteriostatic, often with no distinction between activities in a variety of previous studies ${ }^{26}$. Recent data in literature has the tendency to characterize chitosan as bacteriostatic rather than bactericidal ${ }^{26}$, although the exact mechanism is not fully understood. However, the mechanism of antibacterial activity of chitosan against $E$. coli is that it could make the bacteria flocculate and kill it. In addition, our results revealed that chitosan is able to kill a lot of the live bacteria ${ }^{4-7}$, while some of the live bacteria were only inhibited by chitosan ${ }^{10}$. Therefore, it could be suggested that bacteriocidal or bacteriostatic activities of chitosan depend on the target bacteria.

Membranes destruction or disruption?: Surface interference may be the possible mechanism for the bactericidal properties ${ }^{9}$. Several studies have indicated that the interactions between positively charged chitosan molecules and negatively charged residues on the bacterial cell surface play an important role in the inhibitory effect of chitosan on bacteria ${ }^{9}$. This charge interaction can alter bacterial surface morphology, which either increases membrane permeability, causing leakage of intracellular substances, or decreases membrane permeability, preventing nutrient transport ${ }^{25}$. In particular, visual confirmation of an effective membrane destruction of chitosan and its derivative has been reported in both gram-positive and gramnegative bacteria ${ }^{25,27}$.

However, several studies indicated that chitosan's effect might not be as dramatic as lysing bacterial cells. The interaction between chitosan and $E$. coli did not involve the release of LPS or other membrane lipids ${ }^{25}$ while chitosan treatment of Staphylococcus simulans 22 cells did not lead to cell wall lysis and the cell membrane remained intact ${ }^{2}$. In addition, chitosanarginine's effect on bacteria was not as violent as that of known bactericides $^{25}$. Rather, chitosan permeabilized bacterial envelopes and affected plasma membranes, which likely leads to the leakage of small intracellular substances, or allows other substances to enter into cells, eventually killing the bacteria ${ }^{25}$. These contrasting results may be attributed to the difference in bacterial species.

The charge density on the cell surface is a determinant factor to establish the amount of adsorbed chitosan ${ }^{26}$. However, previous work from the literature has not lead to any conclusive data as to whether the chitosan has higher activity on grampositive or on gram-negative bacteria ${ }^{26}$. It has been demonstrated that hydrophilicity in gram-negative bacteria is significantly higher than in gram-positive bacteria, making them more sensitive to chitosan ${ }^{26}$. In addition, the outer membrane of gram-negative bacteria consists essentially of lipopolysaccharides which render to the surface a density of negative charges superior to that observed for gram-positive ones ${ }^{26}$. This supports the evidence that the leakage of intracellular material 
observed by chitosan in gram-negative is superior to that reported in gram-positive bacteria. However, some authors have stated that chitosan generally showed stronger effects for gram-positive bacteria than for gram-negative bacteria ${ }^{26}$. This would suggest that the antibacterial mode of action is dependent on the host bacteria.

Binding of DNA: Another proposed mechanism in literature is the binding of chitosan with microbial DNA, which leads to the inhibition of the mRNA and protein synthesis via the penetration of chitosan into the nuclei of the microorganisms ${ }^{26}$. Most literature reported chitson and its role on the inactivation of replication and the stoppage of multiplication and spread of the virus or viroid ${ }^{8}$. Recently, it has been postulated that positively charged chitosan binds with cellular DNA following chitosan penetration into the cells, thereby inhibiting transcription $^{28}$. And the chitosan molecule is assumed to be able to pass through the bacterial cell wall and reach the plasma membrane. Observation by confocal laser scanning microscopy confirmed the presence of chitosan oligomers inside $E$. coli exposed to chitosan under different conditions ${ }^{26}$. In contrast, several studies indicated that chitosan penetration into microbial cells is unlikely to occur because of its macromolecular polymeric structure ${ }^{29}$.

Nutritional block: The chitosan excellent metal-binding capacities to vital nutrients for microbial growth and the uptake of metal cations by chelation, is the third mechanism ${ }^{9,26}$. Moreover, according to some reports chitosan's some characteristics, in particular, its abilities to chelate trace metals, might shed some light on its antimicrobial mode of action ${ }^{2}$. However, such mechanism is more efficient at high $\mathrm{pH}$ where positive ions are bounded to chitosan, since the amino groups are unprotonated and the electron pair on the amino nitrogen is available for donation to metal ions ${ }^{26}$. Chitosan molecules in bacteria surrounds might complex metals and block some essential nutrients to flow, contributing to cell death ${ }^{26,27}$. Nevertheless, this is, evidently, not a determinant antimicrobial action since the sites available for interaction are limited and the complexation reach saturation in function of metal concentration $^{26}$

Antibiofilm formation: Biofilm formation in pathogenic bacteria that are strongly related to disease is an active field of research. A recent study showed that chitosan-coated surfaces have antibiofilm properties in vitro against certain bacteria and fungi $^{30,31}$. Additionally, chitosan nanoparticles can effectively reduced the biofilm bacteria, disrupt biofilm structure and retain antibacterial property even after aging ${ }^{32}$. However, zeta potential analysis demonstrates that chitosan has a profound effect on the negative charge of the cryptococcal cellular membrane, which may translate into interference with surface colonization or adhesion and cell-cell interactions during biofilm formation ${ }^{31}$. However, little information is available about the role of antibiofilm formation in antibacterial activity of chitosan.

Series of molecular events: The mode of action of chitosan is probably more complex than initially assumed, involving a number of events that may ultimately lead to a killing process ${ }^{2}$. In general, it seems that chitosan's mode of action is not restrained to a single target molecule but that killing results from a sequence of rather "untargeted" molecular events, taking place simultaneously or successively. Nevertheless, the complex mechanisms by which these processes are coupled or interrelated have not been fully ascertained.

Indirect action mode: In addition to direct antimicrobial or toxic agent, chitosan is often used in plant disease control as a powerful elicitor. Indeed, chitosan applied to tomato plants in advance of $R$. solanacearum inoculum induced resistance to this tomato pathogen by accumulating defense response proteins ${ }^{12}$. In general, El Hadrami et al. ${ }^{8}$ has recently summarized the applications as a plant elicitor and action codes of chitosan and its derivatives in plant protection.

\section{Conclusion}

Chitosan and its derivatives have been getting more and more attention in sustainable agriculture. Examination of better ways to incorporate chitosan and their derivatives into agriculture remains to be pursued. In addition to direct antibacterial activity, chitosan in agriculture is often used in plant disease control as a powerful elicitor. Despite the multiple potential applications of chitosan, we believe that applications of chitosan in agriculture are the most promising in the future.

\section{ACKNOWLEDGEMENTS}

This project was supported by National Natural Science Foundation of China (31371904), Zhejiang Provincial Natural Science Foundation of China (R13C140001; LQ13C140001), Zhejiang Provincial Project (2010R10091), the Fundamental Research Funds for the Central Universities, the Agricultural Ministry of China (nyhyzx 201003029; 201003066; 201303015), Zhejiang Normal University Funds (ZC304013019), State Education Ministry, Key Subject Construction Program of Zhejiang for Modern Agricultural Biotechnology and Crop Disease Control (2010DS700124-KF1101; 2010DS700124KF1203 and 2010DS700124- KF1309).

\section{REFERENCES}

1. F. Khoushab and M. Yamabhai, Mar. Drugs, 8, 1988 (2010).

2. D. Raafat, K. von Bargen, A. Haas and H.G. Sahl, Appl. Environ. Microbiol., 74, 3764 (2008).

3. M. Aider, LWT-Food Sci. Technol., 43, 837 (2010).

4. B. Li, X. Wang, R.X. Chen, W.G. Huang and G.L. Xie, Carbohydr. Polym., 72, 287 (2008).

5. B. Li, B.P. Liu, T. Su, F. Wang, Q.M. Tang, Y. Fang, G.L Xie and G.C. Sun, Plant Pathol. J., 26, 189 (2010).

6. B. Li, T. Su, X.L. Chen, B.P. Liu, B. Zhu, Y. Fang, W. Qiu and G.L. Xie, Appl. Ento. Zool., 45, 145 (2010).

7. B. Li, R.R. Yu, B.P. Liu, Q.M. Tang, G.Q. Zhang, Y.L. Wang, G.L.Xie and G.C. Sun, Braz. J. Microbiol., 42, 96 (2010).

8. A. El Hadrami, L.R. Adam, I. El Hadrami and F. Daayf, Mar. Drugs, 8, 968 (2010).

9. I.M. Helander, E.L. Nurmiaho-Lassila, R. Ahvenainen, J. Rhoades and S. Roller, Int. J. Food Microbiol., 71, 235 (2001).

10. Y. Fang, M.M. Lou, B. Li, G.L. Xie, F. Wang, L.X. Zhang and Y.C. Luo, World J. Microbiol. Biotechl., 26, 443 (2010).

11. M.M. Lou, B. Zhu, I. Muhammad, B. Li, G.L. Xie, Y.L. Wang, H.Y. Li and G.C. Sun, Carbohydr. Res., 346, 1294 (2011).

12. S.A. Algam, G.L. Xie, B. Li, S.H. Yu, T. Su and J. Larsen, J. Plant Pathol., 3, 595 ( 2010).

13. E.I. Rabea, M.E.I. Badawy, W. Steurbaut and C.V. Stevens, Eur. Polym. J., 45, 237 (2009).

14. M.E.I. Badawy, J. Appl. Polym. Sci., 117, 960 (2010).

15. O. Acar, C. Aki and H. Erdugan, Fresen. Environ. Bull., 17, 797 (2008).

16. T. Toda and B.L. Toda, Patent number: JP1203311-A (1989).

17. J. Beausejour, N. Clermont and C. Beaulieu, Plant Soil, 256, 463 (2003). 
18. F.R. Cavalcanti, M.L.V. Resende, C.P.S. Carvalho, J.A.G. Silveira and J.T.A. Oliveira, Crop Prot., 26, 729 (2007).

19. B. Li, G.L. Wang, Z.Y. Wu, W. Qiu, Q.M. Tang and G.L. Xie, Plant Dis., 93, 1219 (2009).

20. B. Li, R.R. Yu, S.H. Yu, W. Qiu, Y. Fang and G.L. Xie, Plant Pathol. J., 25, 91 (2009).

21. B. Li, Y. Fang, G.Q. Zhang, R.R. Yu, M.M. Lou, G.L. Xie, Y.L. Wang and G.C. Sun, Plant Pathol. J., 26, 223 (2010).

22. J. Feng, J. He, Z. Ma, Z. Wang and X. Zhang, Patent number: CN101305747-A(2009).

23. A. Uthairatanakij, J.A. Teixeira da Silva and K. Obsuwan, Orchid Sci. Biotech., 1, 1 (2007).

24. H. Honarkar and M. Barikani, Monatsh. Chem., 140, 1403 (2009).

25. H. Tang, P. Zhang, T.L. Kieft, S.J. Ryan, S.M. Baker, W.P. Wiesmann and S. Rogelj, Acta Biomater, 6, 2562 (2010).
26. R.C. Goy, D. de Britto and O.B.G. Assis, Polim.-Cienc. E Technol., 19, 241 (2009).

27. A.B. Vishu Kumar, M.C. Varadaraj, L.R. Gowda and R.N. Tharanathan, Biochim. Biophy. Acta, 1770, 495 (2007).

28. S.H. Lim and S.M. Hudson, J. Macromol. Sci. C-Polym. Rev., 43, 223 (2003).

29. L.J. Quito-Teixeira, I. Odriozola-Serrano, R. Soliva-Fortuny, A. MotaRamos and O. Marton-Belloso, J. Sci. Food Agric., 89, 2636 (2009).

30. R.P. Carlson, R. Taffs, W.M. Davison and P.S. Stewart, J. Biomater. Sci.-Polym. E, 19, 1035 (2008).

31. L.R. Martinez, M.R. Mihu, G. Han, S. Frases, R.J.B. Cordero, A. Casadevall, A.J. Friedman, J.M. Friedman and J.D. Nosanchuk, Biomaterials, 31, 669 (2010).

32. A. Shrestha, Z. Shi, K.G. Neoh and A. Kishen, J. Endod., 36, 1030 (2010). 